\title{
PARIS: PROLEGÔMENOS DE UMA CIDADE MODERNA
}

DOI: http//dx.doi.org/10.15448/2178-3748.2017.2.22416

Edson Santos Silva Professor Adjunto C na Unicentro/ Irati e professor do PPGL na mesma instituição jeremoabo@ig.com.br

Wallas Jefferson de Lima Doutorando em História pela Universidade Federal do Paraná - Bolsista CAPES wallasjefferson@hotmail.com

HARVEY, DAVID. Paris: Capital da Modernidade. Tradução Magda Lopes. São Paulo: Boitempo, 2015.

Conhecido como um dos grandes intérpretes do Marxismo na atualidade, David Harvey revela-se, também, como um dos maiores expoentes da chamada Critical Geography. Formado pela University of Cambridge, onde obteve seu doutorado em 1961, este geógrafo britânico tem especial afeição pelo estudo e pela análise das transformações econômicas, sociais, históricas e culturais do espaço urbano. Professor emérito de antropologia da City University of New York, Harvey explora em suas pesquisas o domínio dos diferentes circuitos do capital e os processos relacionados à intensificação do sistema de crédito e consumismo ostentatório, focando-se no estudo dos atores da produção do espaço. Essas problemáticas atravessam o caleidoscópio de suas análises: em Social Justice and the City, de 1973, ele já demonstrava um fascínio por temas relacionados ao planejamento urbano, à desigualdade de renda entre bairros ricos e pobres e à formação espacial da cidade. Por meio de uma crítica contundente, ele desenvolveu a ideia de que a formulação de uma teoria contrarrevolucionária em Geografia só seria possível via marxismo. Suas investigações têm contribuído para demonstrar como o capitalismo aniquila o espaço, no intuito de garantir sua própria reprodução, como se pode constatar em Condition of Postmodernity, de 1989. Como um dos mais destacados especialistas desse campo, Harvey também produziu reflexões a respeito das crises econômicas do capitalismo (The enigma of Capital, publicado em 2010) e das características atuais do imperialismo (The New Imperialism, publicado em 2003). Publicado originalmente em 2003, Paris: capital da Modernidade revela 
a preocupação do autor com questões relacionadas ao denominado "direito à cidade" (Henri Lefebvre), elemento constitutivo de sua trajetória. David Harvey esteve no Brasil em junho de 2015, para lançar a versão traduzida dessa obra no Seminário Internacional Cidades Rebeldes, momento em que debateu questões relacionadas às atividades econômicas, aos hábitos sociais, às estruturas de poder e à consolidação da expansão do sistema capitalista.

Para Harvey, a história do que aconteceu na Paris do Segundo Império (1852-1870) de Napoleão III é um emaranhado de relatos de repressão, destruição e cooptação. Recorre o autor ao modo dialético e relacional de investigação teórica a partir de um minucioso trabalho em arquivos parisienses, tendo como fontes de pesquisas obras literárias, caricaturas de Honoré Daumier - que reproduzem quase sempre a vida diária, a política e a economia da Paris do Segundo Império -, mapas históricos, fotografias e gráficos do período. Auxiliado pela metodologia do materialismo histórico-geográfico e recorrendo ao modo dialético e relacional de investigação, a partir de uma releitura dos escritos de intelectuais e ativistas políticos (em especial, Saint-Simon, Louis Blanqui, Robert Owen e Étienne Cabbet, Karl Marx, Pierre Leroux e Flora Tristan), Harvey reconstrói os embates e dilemas político-sociais da Paris do Segundo Império.

O livro, que faz o leitor apegar-se do início ao fim, compõe-se, em linhas gerais, de três partes bastante autônomas. A primeira parte, Representações: Paris 1830-1848, é uma versão revisada e ampliada de estudos anteriormente publicados pelo pesquisador em Cosmopolitan Geographies, organizado por Vinay Dharwadker, em 2001. Realizando uma crítica do que chama "mito da Modernidade", Harvey sustenta que a suprema realização de Honoré de Balzac foi representar as forças sociais da sociedade burguesa parisiense, abrindo perspectivas amplas acerca do que era a Paris antes da Revolução de 1848, voltando-se, na maior parte das vezes, ao tema da aristocracia e sua busca pelo poder. Balzac descreveu as minúcias das relações sociais, expressas por meio dos espaços idilicamente construídos para a burguesia. Suas obras criticam, com toques de ironia, as negações de tais relações e demonstram o total vazio dos valores baseados nos cálculos monetários. Exibem, segundo Harvey, um universo de constelações e confrontos de forças de classe. O livro resgata, ainda, a eflorescência de ideias utópicas, revolucionárias e reformistas entre 1830 e 1848. Destaca que o legado dos pensadores e intelectuais progressistas como Saint-Simon, Blanqui, Proudhon e Cabet, que refletiram acerca da relação entre civilização e comércio, o poder político aristocrático, o crescimento do individualismo, a propriedade privada e o crédito e a corrupção no aparelho estatal. 
A segunda parte, Materializações: Paris 1848-1870, explora a questão urbana propriamente dita. Trata-se de uma versão revisada e ampliada do ensaio Consciousness and the Urban Experience, publicado pela Johns Hopkins, na University Press, em 1985. Harvey explica que a busca pela Modernidade começou antes que o barão Georges-Eugène Haussmamm, prefeito de Paris de 1853 a 1870, transformasse radicalmente a cidade. Haussmamm apresenta-se, à primeira vista, como um político que possuía uma percepção de total ruptura com o passado. Sua intenção era mostrar aos franceses que ele era o único capaz de realizar um projeto de modernidade e modernização da sociedade francesa, em detrimento de outros grupos políticos da época como os republicanos, os monarquistas, os jacobinos e os grupos de esquerda. Entretanto, suas ideias não passavam de uma versão radical da doutrina estética que então dominava o pensamento europeu há anos. Era um bonapartista autoritário, ambicioso, obcecado pelos detalhes do alinhamento e da assimetria. Fascinado pelo poder, ele "estava preparado para ir muito longe na busca de seus objetivos" (p. 139). Suas escolhas estéticas e seus projetos de mobiliário urbano (como a iluminação a gás, os quiosques, a divisão da cidade em arrondissements e até os mictórios de rua conhecidos como vespasiennes) estão relacionados com grandes mutações ideológicas da época. O processo de transformação urbana de Paris - apelidada de "Haussmannização" por Harvey - não foi um simples processo de demolições de edifícios antigos e construções de novos. Ocorriam, paralelo a isso, mudanças significativas nas organizações locais, no acesso ao crédito e aos aluguéis, nas políticas oficiais do Estado e na cultura francesa. Alterava-se, também, o mercado de trabalho face ao crescimento populacional. Fruto de um contexto histórico específico, estas alterações urbanas só se tornaram possíveis graças a uma coalizão entre o Estado francês, o capital financeiro e o interesse mobiliário.

Buscando emergir o novo rejeitando a tradição, Haussmamm não poupou esforços para embelezar Paris. Focava, antes de tudo, na melhoria das relações espaciais e na reorganização do sistema de transporte e de comunicações. Seus investimentos cobriram "não apenas uma nova rede de ruas, mas também esgotos, parques, monumentos e espaços simbólicos, escolas, igrejas, prédios administrativos, moradias, hotéis, instalações comerciais, etc". (p. 153). Ainda que a perda da tradição deixasse a História de Paris à deriva (especialmente em relação aos edifícios medievais), reconhecia-se que a Modernidade estava intimamente relacionada ao transitório, ao efêmero. O feitiço que o passado impunha ao presente tinha de ser rompido para dar espaço ao novo. $\mathrm{O}$ conceito de modernidade buscava expressar, portanto, a convicção de que o futuro havia começado. 
Salienta-se, graças aos variados gráficos e dados matemáticos apresentados ao longo da obra, a grande demanda por moradias para a população de baixa renda que, não tendo outra opção, observou quase inerte o seu deslocamento do centro da cidade de Paris para regiões periféricas. Aliás, denuncia o autor, "era de se esperar que Paris estivesse mais geograficamente segregada em 1870 do que em 1850" (p. 189). Com o passar do tempo, tornou-se visível a organização sistemática dos valores e usos da terra, definindo a paisagem parisiense: havia uma enorme diferença entre o oeste burguês e o leste trabalhador, separados basicamente por um centro comercial de alta renda que punha em lados opostos a dinâmica Rive Droite da letárgica Rive Gauche. Esconderijos, becos e ruas estreitas foram varridos e substituídos pelos famosos Boulevares, que permitiam a livre circulação da burguesia nos bairros comerciais e de entretenimento. $\mathrm{O}$ centro de Paris foi entregue aos edifícios monumentais da administração imperial, às finanças, ao comércio e aos serviços em ascensão surgidos em torno do crescente mercado turístico. As novas mudanças geográficas, segundo Harvey, passaram a ser caracterizadas pela diferenciação dos sistemas sociais e econômicos, funcionalmente interligados, cristalizados em torno da elevação dos preços das propriedades e do "aburguesamento" da cidade. O resultado tornou-se claro com o passar dos anos: valorização do centro de Paris e criação de bairros exclusivamente burgueses em oposição à periferia, onde morava a maior parte dos trabalhadores. À medida que o cotidiano foi tomado por esta racionalização geográfica e espacial, dissolveram-se também as formas de vida tradicionais.

A "Haussmanização" de Paris, caracterizada pela expulsão dos operários e pobres do centro da cidade, sinalizou um tipo de prática: serviu para segregar os elementos heterogêneos da cidade. Tal prática de exclusão revela o aspecto cruel do capitalismo, ao forçar uma separação e uma eliminação rigorosas daqueles que deveriam ser levados para um "outro espaço", longe da burguesia ascendente. O que estava em causa, portanto, era a segmentação espacial dos operários, imigrantes e pobres, entregues à própria sorte. A exclusão espacial relaciona-se à valorização da propriedade parisiense e à consequente especulação no mercado imobiliário. Por não conseguir atender às necessidades populares, Paris viu crescer a formação de favelas, como a famosa Petit Pologne, caracterizada pelas más condições e deterioração dos modos de vida dos mais pobres. Todavia, apesar de focalizar a história da remodelação de Paris, Harvey procura dar espaço à superestrutura financeira do Segundo Império francês. Explica, por exemplo, que se as finanças não estivessem organizadas, as transformações urbanas de Paris não teriam saído do papel. Primeiro porque a cidade recorria constantemente a empréstimos e, segundo, porque os projetos de Haussmamm dependiam essencialmente de "companhias que 
tivessem o poder financeiro para desenvolver, construir, comprar e administrar os espaços que ele abriu" (p. 165).

Graças à organização financeira e aos investimentos, houve um aumento do número de indústrias. Como era de se esperar, Paris especializou-se nos chamados "produtos de luxo" (p. 219). Grandes lojas de departamentos foram inauguradas, como o Bon Marché (fundada em 1852), Louvre (1855) e Printemps (1865), tornando-se peças centrais do comércio parisiense. O crescimento da indústria e do comércio exerceu uma forte pressão no mercado de trabalho. Paris possuía uma enorme excedente força de trabalho. O desemprego tornou-se um problema importante na cidade, graças à entrada em massa de trabalhadores provinciais e imigrantes. Harvey estuda não somente a qualidade da mão de obra ofertada nesse período, mas, também, o individualismo competitivo, a sindicalização, as greves, as disputas jurídicas e as relações entre patrões e trabalhadores. A partir de dados relativos às rendas anuais, o pesquisador explica que a elevação no custo de vida neutralizou os salários nominais. $\mathrm{O}$ ingresso de mulheres no mercado de trabalho - outro grande reservatório de mão de obra excedente -, tornou-se atrativo e, em alguns setores, até imperativo, devido aos custos de mão de obra. A condição das mulheres, nesse período, aliás, é abordada em boa parte do livro. Em linhas gerais, o autor defende a ideia de que houve uma forte conexão entre gênero, sexualidade e revolução. O olhar curioso com que Harvey disseca pacientemente as experiências limites das mulheres - da dependência submissa ao marido passando pelas experiências do emprego doméstico e dos traumáticos casos de prostituição -, demonstra que a modernização de Paris trouxe uma série de possibilidades de trabalho para o sexo feminino.

O livro investiga ainda de que maneira o Império buscou transformar os grandes espetáculos - cerimônias na corte, casamentos imperiais, enterros, visitas de autoridades e desfiles militares - em ocasiões de apoio ao poder imperial. Para o autor, a monumentalidade que acompanhou a reconstrução do tecido urbano parisiense "ajudou na legitimação do novo regime" (p. 282). A proliferação dos espetáculos como as Fêtes impériales, os carnavais de Belleville, os cabarés (como o Moulin Rouge), os circos, os concertos, os cafés (centros de socialização e discussão política), os teatros e as casas de ópera atraíam multidões das províncias e do exterior. Parques como o Bois de Boulogne e Monceau, e até praças como a Square du Temple, foram transformados em locais de socialização e lazer, no intuito de estimular novas formas de urbanização que destacassem a exibição pública da opulência privada. Os boulevares foram criados como centros de exibição pública, espaços para a exibição da riqueza burguesa e do consumo ostensivo. A criação da famosa Champs-Elysée e do 
Boulevard des Italiens insere-se nesse contexto. Segundo Harvey, tamanha era a relação simbiótica entre espaços comerciais e públicos que "tornou-se uma necessidade social passear pelos bulevares" (p. 291). Neste ponto, a análise de Walter Benjamin acerca do fascínio de Baudelaire pelo homem na multidão - o flâneur - atinge seu ponto máximo.

A exclusão e o extermínio cada vez mais completo do todo heterogêneo e a transformação da terra e do mercado imobiliário, com os quais se constituía a nova Paris, abalaram não apenas a estrutura socioespacial da cidade, mas as noções tradicionais de comunidade. Harvey não teme construir uma história das classes sociais. Ao contrário. Ele descreve esse período como uma época de consumpção social, caracterizado pelo aumento brutal das desigualdades entre ricos e pobres. Porém, em Harvey, os elementos sociais não aparecem na figura de um destino apocalíptico evocado misticamente, mas como forças subversivas que somente serão descarregadas com compulsão, se antes não forem desencadeadas em uma sociedade socialista libertária. Ele investiga os imperativos da estrutura de classe de Paris e denuncia a grande desqualificação em curso do ofício do trabalhador e de seu poder econômico, e a consequente supervalorização do estilo de vida burguês. Com o passar do tempo, o trabalho e o consumo parisienses se submeteram ao capitalismo para reter no produtivismo industrial uma tendência à autodestruição. $\mathrm{O}$ fosso entre ricos e pobres se alargou ainda mais nesse período. Haussmamm utilizava as obras públicas, as grandes comemorações, a pompa e as sedutoras roupagens para construir uma ideia de senso de comunidade em que o capitalismo era livre. Propagava, dessa forma, uma concepção de comunidade em que o poder do dinheiro era hipervalorizado como espetáculo e exibido nos grandes bulevares e nos cafés. Harvey critica essa visão. Dessa crítica resulta a perspectiva de uma sociedade altamente segregada. Afirma o autor que "o brilho e a riqueza do centro há muito contrastavam com o empobrecimento sombrio do subúrbio; o oeste predominantemente burguês destoava do leste da classe trabalhadora" (p. 319). A Haussmannização de Paris ampliou as distinções de classe, destruindo tanto a ficção da soberania do cidadão quanto a existência alienada do homem gerido por relações desumanas. Paris transformou-se em um incompreensível labirinto caleidoscópico. O aristocrático Faubourg St. Germain, o mundo comercial dos bulevares da Rive Droite, a bolsa de valores, o Palais Royal, a Rue St. Honoré, a região de Sorbonne, os cafés, os parques, jardins e os teatros contrastavam com a eterna presença sombria da classe trabalhadora. Harvey salienta o eterno desejo burguês de, a partir de tais construções, aprofundar as barreiras espaciais que separavam as classes sociais, expondo o total vazio dos valores ditos "burgueses". 
A crítica à modernização de Paris toma uma nova direção em Harvey. Ele utiliza o conceito de divisão do espaço social para explicar de que maneira a burguesia construiu imagens e representações negativas em torno dos trabalhadores. Tratava-se de um desencanto ambivalente, em que a subjetividade de ideias se desfazia de si mesma. $\mathrm{O}$ autor entende que a cisão entre as concepções política e social da República - tão evidente em 1848 - possuía uma grande importância para o período, pois era uma força capaz de curar a fratura originada pelas novas concepções de classe introduzidas pelo capitalismo, pela crescente dominação do capital financeiro e o consequente desafeto paulatino frente às péssimas condições de vida da classe trabalhadora. O autor apresenta os episódios de 1848 como o resultado dessas questões. Para ele, a Comuna de Paris surgiu a partir de uma busca por transformações do poder e relações sociais inseridas no interior de uma determinada configuração de classe. Foi um período importante na História da França, visto que colocou a questão de qual aliança política de classe poderia substituir o Império. Segundo o autor, nem os monarquistas, nem o republicanismo burguês eram capazes - devido às suas próprias contradições e interesses -, de melhorar a vida das classes menos favorecidas. As Revoluções de 1848 aproximavam-se das forças dionisíacas e se voltavam contra o princípio de individualização das relações sociais. Para Harvey, estudar em profundidade a Comuna revela que "grande parte do que aconteceu estava intimamente relacionada nos processos e efeitos da transformação de Paris no Segundo Império" (p. 404).

Por fim, a terceira parte, denominada Coda, a construção da basílica de Sacré-Couer, enfatiza um programa de estudos e análises da história e simbologia de uma das igrejas mais famosas de Paris. Comporta, no essencial, um estudo inicialmente publicado em Annals of the Association of American Geographers, em 1979. Harvey explica que a Sacré Couer foi estrategicamente construída no alto da colina de Montmartre. Ocupando uma posição dominante em Paris, essa igreja possui um estilo característico: impactante e singular, parece suspensa no espaço. Sepulcral e etérea, "projeta uma imagem de grandeza sagrada de lembrança perpétua" (p. 413). Foi Marguerite Marie Alacoque, famosa vidente católica que, assaltada por visões, transformou a adoração ao Sagrado Coração em um culto específico da Igreja católica no século XVII. O culto propagou-se lentamente pela França, exercendo forte influência na vida de Luís XVI e sua família, que se tornaram devotos do Sagrado Coração.

Harvey explica que, com a derrota de Sedan, o Império francês chegou ao fim, mas a guerra continuou. Os exércitos prussianos cercaram Paris, em num cerco que durou vários meses. O povo observou, com um silêncio sepulcral, os prussianos desfilarem pelas ChampsElysées. Alexandre Legentil, respeitável cidadão burguês, jurou então que "se Deus salvasse 
Paris e a França e libertasse o pontífice, ele contribuiria com os recursos que pudesse para a construção em Paris de um santuário dedicado ao Sagrado Coração" (p. 417). O autor passa a destacar então como as forças de Versalhes, sob o comando do general Thiers, atravessaram as zonas burguesas do oeste da cidade e invadiram lentamente os grandes bulevares. Começou então uma das maiores carnificinas da História da França, caracterizada por combates de rua, execuções arbitrárias e muito sangue derramado. Dessa história, mereceu destaque a execução de Eugène Varlin, encadernador e organizador do sindicato e das cooperativas de alimentos no Segundo Império. Varlin foi forçado a caminhar pela encosta de Montmartre, enquanto era espancado e humilhado por uma multidão. Colocado contra um muro, foi fuzilado sob os gritos de "Vive la Commune". Tinha apenas trinta e dois anos de idade. A esquerda acabara de criar um de seus primeiros mártires. Foi exatamente nesse local que se construiu a basílica de SacréCouer. Após os dramáticos episódios da Comuna, Legentil e Rohault de Fleury buscaram o apoio do arcebispo de Paris para levar adiante o projeto de construção da basílica. O arcebispo, animado pelo grande movimento em prol da construção de um monumento em homenagem ao Sagrado Coração, aceitou a responsabilidade pelo empreendimento. Criou-se um concurso para escolher o melhor projeto, vencendo o do arquiteto Paul Abadie. Harvey explica todos os pormenores históricos do período, mostrando as dificuldades técnicas, os altos custos e os interesses econômicos e políticos envolvidos na construção da basílica.

$\mathrm{O}$ autor critica a cisão entre o catolicismo intransigente e o monarquismo reacionário nas relações políticas e nas instituições públicas, sobretudo no que se refere ao assassinato de milhares de communards. Ao longo de toda a obra, Harvey opera com a força de reconciliação de uma razão que não se deixa deduzir imediatamente da subjetividade. Ele acentua constantemente o lado autoritário do Segundo Império e opõe, portanto, o sonho burguês de "afastamento espacial" das classes mais pobres às necessidades reais de luta e participação política, inteiramente distintas, sedimentadas em um contexto de luta de classes. Ora, os tempos modernos haviam conquistado consciência de si por meio de uma reflexão do passado. A oposição entre o espírito de 1789 e os "pecados" da França fora transferida para a Basílica de Sacré-Couer. Com essa consideração, Harvey afirma que "a construção esconde seus segredos em um silêncio sepulcral" (p. 447).

Cabe uma consideração final acerca do significado e valor dessa obra. Paris, capital da Modernidade merece ser estudada com maior atenção pelos historiadores. A partir de sua leitura, o historiador sente-se quase que obrigado a renunciar à ideia de que capitalismo e cidade podem se reconciliar pela via da renovação. O capitalismo produz espaço. A época moderna 
encontra-se, sobretudo nesse livro, sob o signo da liberdade subjetiva. Tal liberdade realiza-se na sociedade, assegurada pelo direito privado, para a persecução dos interesses próprios. Por isso, o conceito de modernização relaciona-se a um conjunto de processos cumulativos: à formação de capital e mobilização de recursos, ao desenvolvimento das forças produtivas, ao aumento da produtividade do trabalho, ao estabelecimento do poder político centralizado, à expansão das formas urbanas de vida e à secularização de valores e normas. Tal noção é, indubitavelmente, o foco da obra de David Harvey.

RESENHA ENVIADA EM: $11 / 11 / 2015$

RESENHA ACEITA PARA PUBLICAÇÃO EM: 30/05/2017 